\title{
Risk Factors of Post-earthquake Fire for Constructions Using the Analytic Hierarchy Process Approach
}

\author{
Hsiaomei LIN \\ Department of Architecture \\ National Taiwan University of Science and Technology \\ Taipei, Taiwan \\ e-mail: berrymei@gmail.com \\ Juicheng KO \\ Guo An Fire Protection Engineering Co., Ltd. \\ Taipei, Taiwan \\ e-mail: kuansince1997@gmail.com
}

\author{
Chingyuan LIN \\ Department of Architecture \\ National Taiwan University of Science and Technology \\ Taipei, Taiwan \\ e-mail: linyuan@mail.ntust.edu.tw
}

\author{
Yushiang WU \\ Department of Mechanical Engineering \\ China University of Science and Technology \\ Taipei, Taiwan \\ e-mail: yswu@cc.cust.edu.tw
}

\begin{abstract}
Urban area is always gathering huge population and different kinds of activities. Once there is any disaster, it would be very possible to have unrecoverable damage. For the post-earthquake fire in constructions, it would caucus damage not only in civilians' lives but also property. Therefore, it becomes an important issue for reducing the damage and casualties in post-earthquake fires. By considering the factors and managing execution for post-earthquake fire in constructions, this research is collecting the statistical data about the experts' opinion, then using Analytic Hierarchy Process (AHP) to analyze, and finalizing the construction of potential risk factors in post-earthquake fires. The five indicators after weighted in all the dimensions are "Well installation of automatic sprinkler equipment", "The application of flame retardant materials", "Unbroken structure of planning fire preventing zone", "Closing of fire doors", and "Execution of fire preventing management". The study result is very close to the potential risk factors of post-earthquake fire from current studies. It shows the relevant factors and the weight constructed by this research are compliant with current situation.
\end{abstract}

Keywords-post-earthquake fire; risk factors; analytic hierarchy process $(\mathrm{AHP})$

\section{INTRODUCTION}

In recent years, it has many cases of earthquake, incl. Chi-chi Earthquake in Taiwan with Richter Scale 7.4 in 1999, Sichuan Province Earthquake in China with Richter 8.0 in 2008, Sumatra Earthquake in Indonesia with Richter Scale 7.6 in 2009, Haiti Earthquake with Richter Scale 7.0 in 2010, Chile Earthquake with Richter Scale 8.8 in 2010, Qinghai Province Earthquake in China with Richter Scale 7.1 in 2010, and Christchurch Earthquake in New Zealand in Feb., 2011, etc.. All the cases bring a lot of casualty. The local fire preventing associations and relevant groups put their focus on the events of post-earthquake fires, and study about fire preventing effects in disasters by both active and passive ways. By the study, it realizes the importance of estimating in the early time of earthquake due to the disaster might cause huge damage in both casualty and economy [1-7].

Nishino T. [8] puts forward the casualty in post-earthquake fire, the location of fire points, wind velocity, wind direction, and distribution of population as the factors. Besides, the study finds out the uncertainty between the relevant factors. For ensuring the safety for the constructions and civilians in this kind of disasters, considering the cases and location of fires, damage of constructions, and the uncertainty in whether the road for rescue is smooth enough or not, this research takes Kyodo, Japan as the research area to discuss 8 types of inland earthquake. By Nishino's study, it evaluates the risk of having damage after disaster in urban area, and uses the result as the reference for having following plans to escape from risk. Therefore, the following research is focusing on the risk factors of having post-earthquake fires in constructions. By using Analytic Hierarchy Process (AHP) to analyze, it would be able to get the weight in different risk factors, and it would be able to reduce the damage or even prevent it.

\section{RESEARCH METHODS}

In using AHP, it would be able to have two parts. One is to build up the levels, and the other is to evaluate the levels. This may be evaluated the factors toward the complicated questions by the experts, and performed by a simple structure with several levels. After that, it would be able to evaluate by having comparison between each factor in scales and build up the matrix for getting the characteristic vector quantities, and have the priorities in different factors in different levels. The following step would check the result of matrix is compliant with the result of consistence test for making sure whether there is 
any mistake and understanding if the result is able to be reference. The Fig.1 would be the flow chart for having AHP.

The following description is about the steps of AHP:

1. Define the questions:

The first step will be defining the questions for understand the purpose and method.

2. List all the factors for evaluation:

When the research is listing the factors, it would need to integrate the opinions for experts and decision makers, and having the advice from them by their knowledge and experience. It will be able to use brainstorming or Delphi method to get the opinion from experts and decision makers.

3. Build up levels:

Put the factors into different levels by the relationship between each other. The Levels shall be defined by the complexity of questions. Each level shall be independent from another.

4. Compare and evaluate:

After building up the structure of levels, the experts would evaluate the sequences for the factors by having comparison for the factors by the importance in the same level. AHP is having 9 scales as the following Table 1:

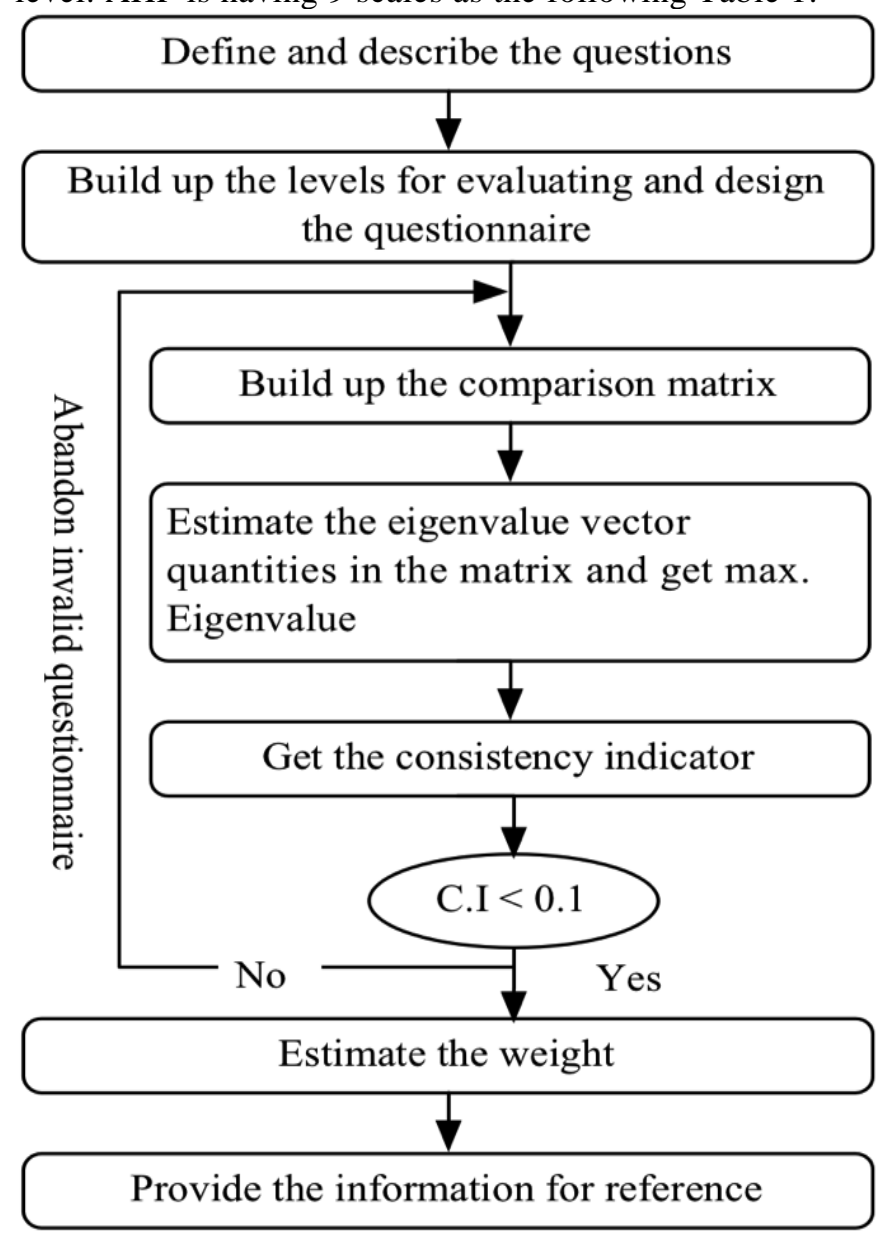

Figure 1. Flow chart for AHP analysis
TABLE I. DESCRIPTION AND SCALES FOR AHP

\begin{tabular}{|c|c|c|}
\hline $\begin{array}{l}\text { Evaluating } \\
\text { scales }\end{array}$ & Definition & Description \\
\hline 1 & $\begin{array}{l}\text { Equal in } \\
\text { importance }\end{array}$ & $\begin{array}{l}\text { Two items are as important as each } \\
\text { other in contribution. }\end{array}$ \\
\hline 3 & $\begin{array}{l}\text { A little bit more } \\
\text { important }\end{array}$ & $\begin{array}{c}\text { Based on experience and } \\
\text { judgment, it is a little bit inclined } \\
\text { to one item than another. }\end{array}$ \\
\hline 5 & $\begin{array}{l}\text { Quiet more } \\
\text { important }\end{array}$ & $\begin{array}{l}\text { Based on experience and } \\
\text { judgment, it is quiet inclined to } \\
\text { one item than another. }\end{array}$ \\
\hline 7 & $\begin{array}{l}\text { Very more } \\
\text { important }\end{array}$ & $\begin{array}{c}\text { Based on experience and } \\
\text { judgment, it is very inclined to one } \\
\text { item than another. }\end{array}$ \\
\hline 9 & $\begin{array}{l}\text { Absolutely more } \\
\text { important }\end{array}$ & $\begin{array}{l}\text { Based on experience and } \\
\text { judgment, it is absolutely inclined } \\
\text { to one item than another. }\end{array}$ \\
\hline $2,4,6,8$ & $\begin{array}{l}\text { Mean between } \\
\text { above two scales }\end{array}$ & When it needs compromise value. \\
\hline
\end{tabular}

5. Estimate eigenvalue and eigenvalue vector quantities:

After building up the comparison matrix, it will be able to use eigenvalue analysis to find out eigenvalue vector quantities, and get the weight for the factors in each level. Once it gets the eigenvalue vector quantities by the max. eigenvalue, it will be the relevant weight for the factors in each level.

6. Consistency test and consistence ratio:

Consistency test is for the decision maker to verify whether the comparison matrix is consistency matrix or not. The decision maker may use consistency indicator (C.I.) and consistency ratio (C.R.) to evaluate the consistency. Once C.I. $=0$, it means the test is consistent. C.I. $\leqq 0.1$ would be allowable margin of error. When C.R. $<0.1$, it means the weight is reasonable.

7. Estimate the priority total vector quantities in all levels:

Once the consistency of all levels is acceptable, the last step will be integrating all the relevant weight of the factors in each level for getting the priority total vector quantities. The vector quantities mean the priority for each plan toward the purpose of decision.

\section{RESUlTS AND DISCUSSION}

After having the interviews with the experts, it will use AHP to have analysis and discussion. By using AHP to have comparison toward the 4 segments for risk factors of post-earthquake fire in constructions, it will be able to estimate the weight value. After that, it will extend comparison into the 13 items to find out the weight for risk factors of post-earthquake fires in constructions from many executive items.

After finishing design for the questionnaire in this research, it will begin sending the questionnaire and the statistical analysis. In this research, it collects 16 questionnaires. After reviewing the questionnaires, two of 
all are incomplete ones that are invalid, and 14 of all are valid ones. By analyzing the interviewees' identity, 3 people are fire-preventing officials, 3 of them are construction relatives, 4 of them are from academy (incl. disaster preventing experts), and 4 interviewees are from construction/fire-fighting overhauling institutes. Therefore, the research result has enough reliability.

After reliability test and validity test, it will be able to get the weight scores for the risk factors of post-earthquake fires. The weight scores and structure are listed in Table 2. It also uses the scores for the risk factors to classify the factors for getting total quantity. Then it takes the classification to judge the risk level for each factor and lists the scores in Table 3.

This research has sent 16 questionnaires and got 14 returns. The returned rate is $87.5 \%$. All the returned questionnaires are tested by consistency ratio (C.R.) for verify the consistency in comparison matrix. All the data in the questionnaires are input into Expert Choice 2000 to have analysis and estimated the weight. The expert data from Group Decision Support System are used for judging the matrix integration by Normalization of the Geometric Mean.
In this research, it builds up the 4 levels for risk factors of post-earthquake fire in constructions and extends 13 items of sub-criteria. After using AHP to the questionnaires from experts for weighting the levels and sub-criteria, the research result shows that "Fire-fighting equipment" has the highest ratio, which is $33.3 \%$ after weighting. It means once the fire-fighting equipment is well assembling would be able to reduce post-earthquake fires. On the other hand, the research result of the extended sub-criteria is shown as the following information:

1. "Status of automatic sprinkler equipment" in "Fire-fighting equipment" has the highest weight, which is $11.9 \%$ by the experts' decision.

2. "Application of fire resistance materials" in "Fire preventing devices" has the second highest weight, which is $11.2 \%$ by the expert decision.

3. "No blocked toward fire preventing zone" in "Fire preventing devices" has the weight, which is $10.6 \%$ by the experts' decision.

4. "Closing of fire door (emergency exit)" in "Fire preventing devices" has the weight which is $10.1 \%$ by the experts' decision.

TABLE II. WEIGHTED TABLE FOR THE RISK FACTORS OF POST-EARTHQUAKE FIRES IN CONSTRUCTIONS

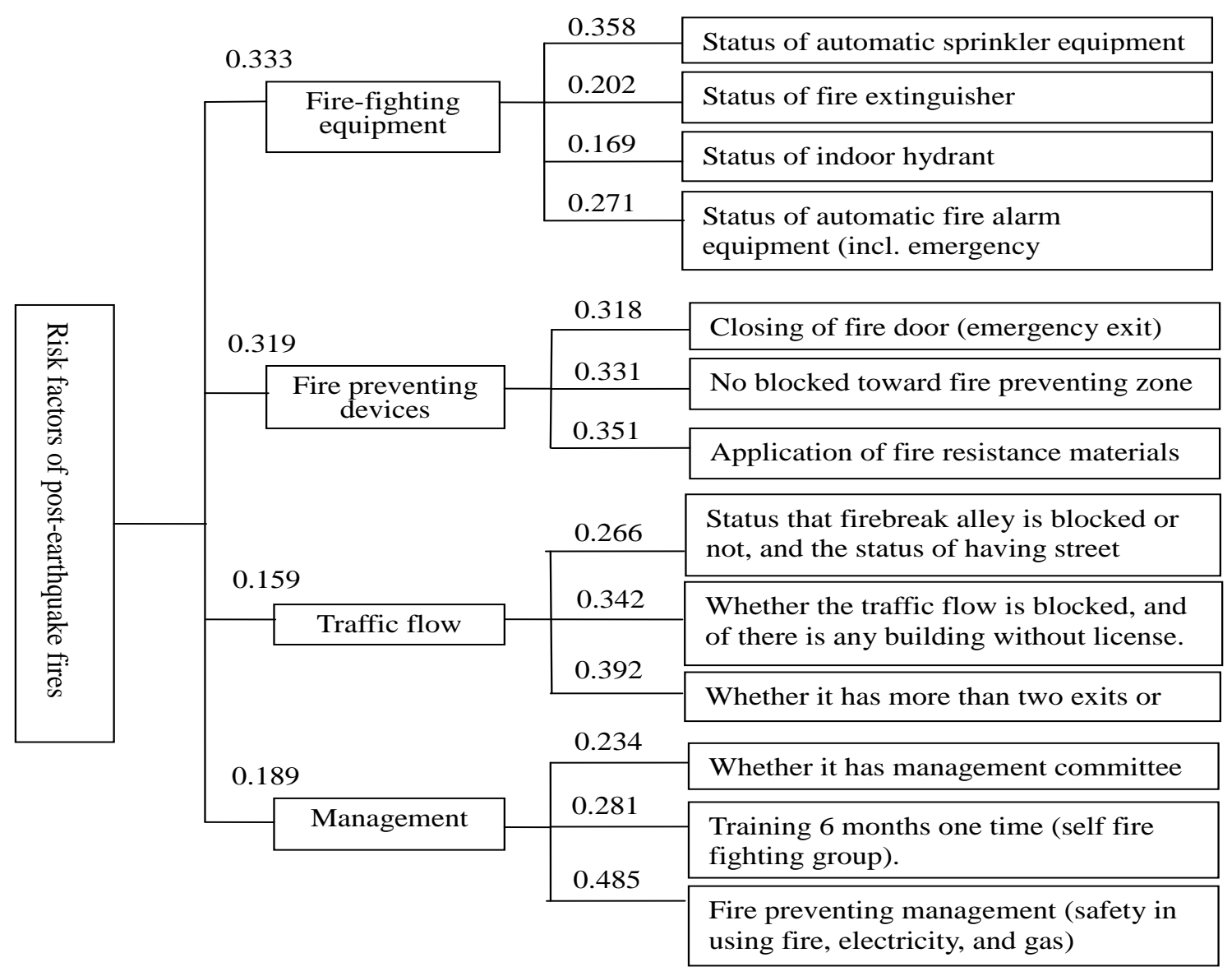




\begin{tabular}{|c|c|c|c|}
\hline Segment (a) & Risk Factor (b) & $\begin{array}{l}\text { Total Weight } \\
\qquad(=\mathrm{a} * \mathrm{~b})\end{array}$ & Sequence in Tota \\
\hline \multirow{4}{*}{$\begin{array}{c}\text { Fire-fighting } \\
\text { equipment }\end{array}$} & 1. Status of automatic sprinkler equipment & 0.119 & 1 \\
\hline & 2. Status of fire extinguisher & 0.067 & 7 \\
\hline & 3. Status of indoor hydrant & 0.056 & 9 \\
\hline & $\begin{array}{l}\text { 4. Status of automatic fire alarm equipment (incl. emergency } \\
\text { broadcasting devices) }\end{array}$ & 0.090 & 6 \\
\hline \multirow{3}{*}{ Fire preventing devices } & 1. Closing of fire door (emergency exit) & 0.101 & 4 \\
\hline & 2. No blocked toward fire preventing zone & 0.106 & 3 \\
\hline & 3. Application of fire resistance materials & 0.112 & 2 \\
\hline \multirow{3}{*}{ Traffic flow } & $\begin{array}{l}\text { 1. Status that firebreak alley is blocked or not, and the status } \\
\text { of having street pedlars on the roads. }\end{array}$ & 0.042 & 13 \\
\hline & $\begin{array}{l}\text { 2. Whether the traffic flow is blocked, and of there is any } \\
\text { building without license. }\end{array}$ & 0.054 & 10 \\
\hline & 3. Whether it has more than two exits or not. & 0.062 & 8 \\
\hline \multirow{3}{*}{ Management } & 1. Whether it has management committee or not. & 0.044 & 12 \\
\hline & 2. Training 6 months one time (self fire fighting group). & 0.053 & 11 \\
\hline & $\begin{array}{l}\text { 3. Fire preventing management (safety in using fire, } \\
\text { electricity, and gas) }\end{array}$ & 0.092 & 5 \\
\hline
\end{tabular}

5. "Fire preventing management (safety in using fire, electricity, and gas)" in "Management" has the weight, which is $9.2 \%$ by the experts' decision.

6. "Status of automatic fire alarm equipment (incl. emergency broadcasting devices)" in "Fire-fighting equipment" has the weight, which is $11.9 \%$ by the experts' decision.

By analyzing the questionnaire and estimating the scores for each key factor, it will be able to get the relevant weight in each key factor, then estimate the quantity of each key factor. By this research, it would be able to make the relevant officials to understand the relevant factors when having plans toward the risk factors of post-earthquake fire in constructions of urban area, so that it will support the execution officials to have more accurate decision and judgment.

\section{CONCLUSION}

Based on the research, it has the following conclusions:

1. By using AHP to have analysis, it is able to have the systemization toward the risk factors of post-earthquake fire in constructions, and it will be able simplify the structure for analyzing by using values.

2. By this research, no matter the interviewees have the same character or not, it finds out that it might have parts of deviation in uncertainty when it is having comparison in two risk factors of post-earthquake fire in constructions.

Therefore, it has to keep revising and scoring for passing the certainty test. From this point of view, it could realize that it has difference in cognition of analysis by the experts.

\section{ACKNOWLEDGEMENT}

This research was thankful for the financial support of the Ministry of Science and Technology of Taiwan under grant No. NOST 104-2511-S-157-001.

\section{REFERENCES}

[1] Y. Hamada, T. Hirono, M. Ikehara, W. Soh, S. R. Song., Estimated dynamic shear stress and frictional heat during the 1999 Taiwan Chi-Chi earthquake: A chemical kinetics approach with isothermal heating experiments, Tectonophysics 469(1-4) (2009) 73-84.

[2] H. Hwang, C. K. Lin, Y. T. Yeh, S. N. Cheng, K. C. Chen, Attenuation relations of Arias intensity based on the Chi-Chi Taiwan earthquake data,Soil Dynamics and Earthquake Engineering 24(7) (2004) 509-517.

[3] B. Dolan, A. Esson, P. Grainger, S. Richardson, M. Ardagh, Earthquake disaster response in Christchurch, New Zealand, Journal of Emergency Nursing 37(5) (2011) 506-509.

[4] S. Milashuk, W. Crane, Pipeline damage caused by transient ground deformation: Case study of 2010 Darfield and 2011 Christchurch earthquakes, Soil Dynamics and Earthquake Engineering 41 (2012) 84-88

[5] Z. Z. Wang, Z. Zhang, Seismic damage classification and risk assessment of mountain tunnels with a validation for the 2008 Wenchuan earthquake, Soil Dynamics and Earthquake Engineering 45 (2013) 45-55.

[6] M. Sarrazin, O. Moroni, C. Neira, B. Venegas, Performance of bridges with seismic isolation bearings during the Maule earthquake, Chile. Soil Dynamics and Earthquake Engineering 47 (2013) 117-131.

[7] Y. Z. Yu, L. J. Deng, X. Sun, He. Lu, Centrifuge modeling of dynamic behavior of pile-reinforced slopes during earthquakes, Journal of Central South University: Science and Technology 17(5) (2010) 1070-1078.

[8] T. Nishino, T. Tanaka, A. Hokugo, An evaluation method for the urban post-earthquake fire risk considering multiple scenarios of fire spread and evacuation. Fire Safety Journal 54 (2012) 167-180. 